\title{
Supplier Relationship Management Goes Digital: First Empirical Insights
}

\author{
Elisabeth Fröhlich $^{1, *}$, Kristina Steinbiß ${ }^{2}$ \\ ${ }^{1}$ CBS International Business School, Germany \\ ${ }^{2}$ ESB Business School, Reutlingen University, Germany
}

Received November 24, 2019; Revised February 25, 2020; Accepted March 12, 2020

\begin{abstract}
Copyright $\odot 2020$ by authors, all rights reserved. Authors agree that this article remains permanently open access under
\end{abstract} the terms of the Creative Commons Attribution License 4.0 International License

\begin{abstract}
In an increasingly competitive environment, suppliers are now seen as an important source of innovation. Long-term partnerships enable companies to access the knowledge of suppliers to optimize their business. "Procurement 4.0" is one of the concepts that come to the fore when talking about digitalization of business processes. The major aim of this research is to discuss a conceptual model of "Procurement 4.0" and its potential to rethink the management of supplier relationships, which will be one of the main future tasks of procurement. The paper is based on a factual-analytical research approach that serves to continuously specify and supplement the elements of the frame of reference: Two challenging concepts, "Procurement 4.0" and Supplier Relationship Management, are merged to contribute to the fact that purchasing is indispensable as an "interface" within a global supply chain to reap the benefits of digitization. The factors that prove to be obstacles to digital supplier relationship management along the digital supplier journey - e.g. lack of guidelines, approaches or tools and a lack of understanding of the importance of long-term relationships - are reflected within the identified technologies of digital transformation. A comprehensive analysis of the given situation within digital supplier relationship management in Germany is provided. The most important digital supplier touchpoints are discussed in order to develop a traditional supplier relationship towards a digital relationship management. Thus, this paper succeeds in illustrating how the innovative concept of a supplier journey can be implemented in practice to counteract the future, entrepreneurial challenges.
\end{abstract}

Keywords Supplier Relationship Management, Procurement 4.0, Digitalization, Strategic Procurement, Digital Purchasing, Maturity Models in Procurement, Supplier Journey

\section{Introduction}

The growing individualization and dynamics of sales markets demand the agility and flexibility of companies. Product development cycles must be shortened in order to meet the ever-increasing demands of consumers. As a result, markets are becoming less predictable, while the cost and innovation pressures for companies are steadily rising. Especially as pertains to procurement, this drives the need for purchasing processes to become increasingly more efficient and therefore leaner. Thus, procurement continues to increase its value proposition for entrepreneurial competitiveness [1]. In the future, the focus will no longer solely remain on cost reduction (generation of "savings") but will manifest itself above all in the implementation of measures that contribute to strategic competitive differentiation [2]. The key questions for the future include the following: How can purchasing meet these new challenges? How can measures be developed and evaluated that support the overall corporate goals?

This fundamental strategic change cannot be managed by the procurement function alone; rather, it will be realized in cooperation with the suppliers. Similarly, in the future the supplier will not be "just" another link in the supply chain, but will additionally promote innovation and digitization as an internal resource of the procuring company [3]. 'Managing the supplier network becomes the heart of the procurement function in the future..., companies and their strategic suppliers find themselves in the same boat $-\mathrm{a}$ boat that to a large extent is steered by procurement' (2).

\section{Methodology}

The development of strategic supplier-buyerrelationships has been defined as an essential enabler for future entrepreneurial success. In various research projects, 
the two researchers have already answered parts of the provided research question at hand. The aim of this article is now to bring the different study results into an overall context in order to answer the research topic of this paper. Based on the establishment of a "Procurement 4.0 Model", different qualitative and quantitative results of the authors' research work [4,5] on the topic of how digitalization can add value for purchasing are used to realign a digital partner model with suppliers. Thus, the scientific contribution of this paper is to further develop the strategic view of purchasing.

As a theoretical framework for the development of the model on hand (see figure 1), the portfolio approach of Kraljic [6] has been chosen [4]. Its basic idea is to identify strategically relevant procurement objects based on two dimensions: value contribution and procurement risk. In general, it is a matter of managing existing resources from different entrepreneurial fields of activity according to the greatest prospect of success. The portfolio has then been adopted to the digitalization of procurement. With focus on the strategic thrusts of procurement, two corresponding dimensions have been derived: 4.0 potential and relationship intensity.

As the topic of digitization is developing rapidly, individual results have been expanded and the researchers' own findings have been added. Digital components and procurement dimensions were selected to provide an understanding of 4.0 and to build upon previous research.

The initial study's aim was to derive and review the developed model of procurement 4.0. Therefore, a qualitative study with high quality primary data, 'data unique to [this] particular study' (7) has been conducted. That included versatile interviews with agreed concepts and credible participants [8] to secure a broad understanding of the digital impact on procurement and its dimensions [9]. The participants were a diverse yet strong primary unit of procurement professionals from buyer to Chief Digital Officer [10]. Importantly, all participants engaged voluntarily with the project and interview arrangement. Preparation was supplemented with an aide-memoir set of guidelines [11] and execution was of a high ethic and supportive standard [12]. Naturally, questions were open to ensure full consistency with the process of qualitative research [10] and 'secured new ideas, fresh insights, and unanticipated concepts and themes in the data' (13).

Concerning the impact of digitalization on supplier relationship management, a deductive quantitative research design on the example of one of the biggest energy suppliers in Europe is the second fundamental study (see for further detail chapter 5.2) on which this paper is built on [5]. Within that research, different main approaches were adopted: First, a self- administered online questionnaire among the whole procurement department, which allows reaching a large sample size. Second semi- structured interviews among selected procurement experts and among strategically important suppliers to receive deeper insights into the supplier management of the business case and to increase flexibility and possibly add further questions if needed during the interviews [14].
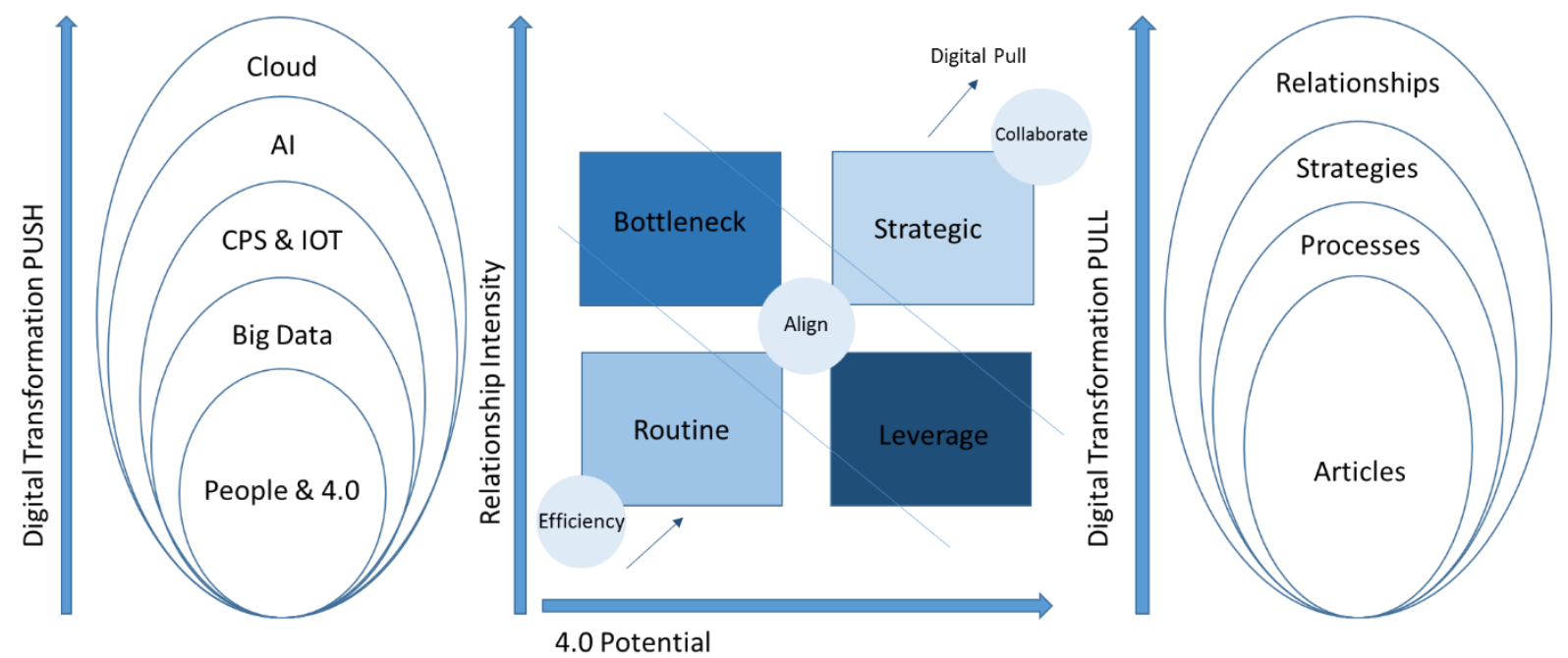

Figure 1. A conceptual model of Procurement 4.0 [4] 
The lack of a systematic-scientific approach to the digitalization of supplier relationship management requires the generation and integration of new findings into the research process to verify or falsify them in a further step. According to the research question, the factual-analytical research strategy seems appropriate to the studies purpose. The factual-analytical research strategy is '(...) oriented towards the penetration of complex interrelationships and the development of bases for action (...)' (15). It serves to continuously specify and supplement the elements of the framework of reference without empirically testing them. The methodology is based on a continuous thought process that starts from known variables taken from underlying studies, alternately clarifying and extending them in order to arrive at new variables and assumptions about cause-effect relationships, which in turn are clarified and extended.

By applying this research strategy the study on hand reveals the main white spots of digitalization on supplier relationship management. By mirroring the five identified problem areas as a result of the quantitative case study with the push factors taken from the developed model of procurement, enriched with aspects of artificial intelligence, the study provides a comprehensive analysis of the given situation within digital supplier relation management.

\section{Requirements for Digital Purchasing}

In order to establish a digitization strategy in purchasing, it is necessary to define the "maturity level" of the company's procurement function [4].

- Pertaining the first maturity level ("Ad hoc"), procurement is defined as a purely reactive function without a strategic direction. Most of the time is spent on routine transactions. The purchasing department has a very low profile within the company and is hardly involved in any possible cooperation. Suppliers are selected according to price and availability, and many processes are correspondingly rather unstructured.

- At level two ("Independent"), current procurement trends and techniques are adopted and purchasing acts as a separate entrepreneurial entity. At this level the focus is on cost efficiency. The connection to technical enterprise functions exists and the top management recognizes the possible value contribution of the procurement department. Supply chain management processes are defined and documented.

- If procurement supports the company's competitive strategy, this stage is referred to level three ("Supporting"). Purchasing is increasingly strategically oriented and integrated into sales processes. Suppliers act as a valuable resource. A regular analysis of internal relations (intralogistics) and external relations with customers and suppliers takes place.

- At maturity level four ("Integrative"), sourcing is an integral part of corporate strategy and actively participates in the formulation of long-term goals and strategies. Cross-departmental, established communication networks with all functional areas are expanded. The performance of procurement is measured by the value contribution to the company's success.

- At maturity level five ("Extended / Digital"), procurement drives the conceptual model of digitization. This will be discussed in the following chapter.

By establishing a digital buyer-supplier-relationship, procurement creates competitive potential. New technologies enable a flexible and systematic assessment of the performance level of current but also potential suppliers, where concrete information is not yet available within the purchasing function [16]. In order to fully exploit this potential, this relationship needs to be integrated in the company's overall strategy. Hence, the basis for digital transformation of supplier management is found in maturity level four [17]. Accordingly, the emphasis of procurement activity initially needs to be on a clear definition of process optimization goals within the wider context of a consistent focus on the overall entrepreneurial target structure. Hence, the necessary reorientation of purchasing function [1] also requires an organizational and personnel realignment as well as a consistent integration into the management and measurement systems of the overall organization. Ultimately, if customer satisfaction is to be prioritized as a future competitive advantage, the introduction of new methods in purchasing activities is unavoidable.

\section{A Conceptual Model of Procurement 4.0}

The original conceptual model of Procurement 4.0 [4] is based on four fundamental "drivers" of digital transformation. As already stated, the use of new technologies is changing rapidly. For this reason, the "push factors" have been extended to include artificial intelligence applications such as chatbots or guided buying. Blockchain Technology is not covered here due to the fact that possible fields of applications are as yet limited. In the future, however, a significant improvement in transparency in the supply chain is anticipated [18].

Building on the individualization of products in the context of Industry 4.0 and the integration of customers and other relevant stakeholders (people) into the business processes, procurement creates value primarily through collaboration [19] and real-time information along the entire value chain [20]. McKinsey Studies[20] assume that 
the use of digitization within the procurement department among other changes enables a reduction up to $40 \%$ of maintenance costs. Furthermore, the time-to-market can be reduced by up to $50 \%$ and the immense amount of data allows an $85 \%$ increase in forecast reliability. Therefore, companies might pass on the resulting cost-cutting potential directly to their customers.

Another important "push factor" is Big Data. The vast amounts of data available to the procurement department come from various business-sectors and innumerable sources. Special solutions are necessary to adequately store, process and evaluate these data volumes. In future, a company's competitiveness will be predominantly determined by the handling of digital data streams in a professional way [22]. This enables companies to better predict and control their core processes, since the data flow along the product life cycle is one of the least used sources of innovation [23]. The potential for purchasing results from the integration of cross-functional product development databases, as well as data-driven process analytics activities [24]. Building a Big Data value chain to solve long-term data security issues is essential.

Cyber-physical systems (CPS) and the Internet of Things (IoT) are further digital drivers of transformation in the model outlined here. CPS are systems with embedded software, which have sensors and actuators [25], evaluate and store recorded data, communicate with each other and in global networks, use worldwide available data and services, and have human-machine interfaces [26]. CPS can be used to interlink data from production logistics, capacity planning and quality assurance (machines maintenance) in real time. IoT, on the other hand, refers to the networking of objects with the Internet so that these objects can communicate independently via the Internet and thus perform various tasks for the user. The scope of application extends from general information supply via automatic orders to warning and emergency functions [27].

Artificial intelligence (AI) describes systems and approaches that can learn behavior through repetition. For example, AI can support natural patterns of human interaction [28] in the context of buyer-supplierrelationships. A distinction is made between Assisted Intelligence, Automated Intelligence, Augmented Intelligence and Autonomous Intelligence [29]. This also includes robot-controlled process automation (RPA). This is less concerned with the specifics of the robot than with the software that saves the purchasing department time-consuming manual work. It copies the activity of a human action such that, for example, supplier databases can be maintained automatically. Another application are chatbots or intelligent assistants [30]. Machine learning can be used, for example, to learn guidelines for the setup of buyer-supplier-relationships. They can also be used by purchasing experts in the search for suppliers, their evaluation, or even in the context of negotiations (so-called Guided Buying)

The final relevant driver of digitization is Cloud Computing. It includes technologies and business models to provide IT resources dynamically. These IT resources are available on demand and flexibly in the form of a service-based business model (via Internet or Intranet) [31]. Beside the reduction of hardware costs with optimal use of computer power, the main advantage for a purchasing department lies in saving license fees and implementation costs of systems [32]. Despite possibly limited financial resources, the purchasing department receives access to relevant data. On the other hand, this data is stored outside the company and thus may pose a security risk.

For the model on hand, the portfolio approach of Kraljic [6] has been chosen. As applied to the digitalization of procurement, this means that the core dimensions of " 4.0 potential" and "relationship intensity" are considered crucial to drive transformation.

Considering the first dimension, the 4.0 potential, it needs to be recognized that digital transformation is "people-driven". People are stakeholders who - in combination with 4.0 - are the instigators for the push for digitalization, which produces Big Data, enabling CPS and IoT respectively. The Cloud therefore acts as an umbrella for all digital activities. In addition to the 4.0 potential, the digital transformation pull depends on the second dimension, the relationship intensity, to benchmark the digital pull. Routine articles, processes and transactions should be digitally efficient. Yet these are found at lower levels of relationship intensity and potential 4.0 cumulative value (efficiency). To fully exploit the opportunity for transformation, it is also necessary to implement comprehensive digital engagement within the company's strategies. This is derived from the strategic and collaborative quadrant of the conceptual model that outlines the implementation of digital relationship management. Thus, the digital integration of suppliers constitutes the end of a successful digitization process in purchasing and represents the highest level of interactivity [33].

This model thus has three essential aspects:

- people are the enablers of the digital change in procurement

- purchasing can only move properly towards digitalization if e-procurement solutions are implemented efficiently

- the strategic competitive advantage of digitalizing the purchasing function lies in shaping digital relationships with suppliers.

Since the focus of this paper is not on digital competencies and human resource development opportunities, the first aspect will not be considered. The third aspect will be the focus of further discussion. Therefore, successful implementation of e-procurement solutions will be briefly discussed. 
The most recent BME-Barometer Electronic Procurement[34] reiterates that although companies have recognized the importance of e-procurement solutions, most are yet to develop basic digital processes. In a study conducted by Piesold and Fröhlich[35], five different e-procurement applications were distinguished:

- Requisition to Pay - the basic P2P processes - digitally map operative procurement processes.

- Analysis \& Control: operational procurement processes require the development of KPIs in order to optimally control them.

- Source to Contract (S2C) comprises demand specifications, tenders and the administration of contracts.

- Plan to Strategy (P2S): demand management, procurement market analyses and product group strategies are the focus here.

- $\quad$ SRM can also be mapped partially via e-procurement solutions and forms the focus of the following chapters.

The aforementioned study [35] reports the situation in the energy sector, but arrives at similar conclusions to the BME-Barometer mentioned above. Ultimately, companies primarily automate $\mathrm{P} 2 \mathrm{P}$ processes but see the potential for strategic purchasing and particularly the establishment of digital buyer-supplier relationships, further indicating the importance of the research presented in this paper. One of the biggest challenges in this context is the diverse range of e-procurement solutions used. Here, IT companies are called upon to remedy this situation and offer appropriate solutions for procurement practice.

In accordance with maturity level four, this means that to enable efficient procurement in this model, e-procurement solutions must be implemented at the company's articles and process level. This is a necessary first step facilitating the digital adaptation of the procurement strategies. However, the full digital potential and thus the attainment of maturity level five is only achieved if the focus is also on the realignment of supplier-procurer relations, i.e. the digital collaboration.

\section{The Impact of Digitalization on Supplier Relationship Management}

After discussing the conceptual model of Procurement 4.0 , it is established that digitalization in procurement ("e-procurement") begins with purchasing articles and processes, then continues with strategies and ultimately effects the way in which buyer-supplier-relationships will need to be established in the future. It follows then that in the field of e-procurement 'software tools to computerize procurement emerge, including eRFX, eAuctions, spend cube, eContract, and eCatalogue' (36).

Supplier relationship management is gaining importance for several reasons. The more conventional motives are that supplier expertise can support the cost cutting efforts of the purchasing company. Reducing cost is and will always be the most important target in purchasing alongside the continuity of operations - this serves to minimize risk and to retain the perceived value on the sales market. Purchasing supports the needs of the company's end customers based on quality and availability [37]. The reason for choosing the digital supplier relationship lies in the more recent benefits of supplier relationship management. Companies heavily depend nowadays on the innovative power of suppliers [38]. The focus is on setting up so called "integrated supply chains", where companies try to integrate the suppliers' resources into their own internal supply chain and benefit from the suppliers' assets and competencies suppliers support companies during tough times [39]. In the long term, companies are only as good as their suppliers [40]. This is also true for digitalization, since 'frictionless collaboration accelerates cycle times by improving internal coordination and supplier performance. Leading companies already are harnessing these technologies to speed problem solving and generate greater value for the business' (16).

To exploit the full potential of the new technologies previously discussed, purchasing must adapt the methods by which buyer-supplier-relationships are set up. However, the remainder of this paper will not describe a general collaboration business model [33], but rather focus on concrete examples of how these technologies can be applied in digital relationship management and on which gaps need to be addressed.

\subsection{Status Quo of Supplier Relationship Management in German Companies}

The following content is derived from research conducted at CBS International Business School based on a concrete company case study from the energy sector [41]. The authors are aware that the findings of this case design [42] can only offer an insight into the current challenges companies face when implementing supplier relationship management; it does not lay claim to being a comprehensive representative study. Almost 100 employees were polled about the use and implementation of the supplier relationship management approach in their company. A pretested online questionnaire was used.

However, the major findings of this research can be summarized as follows:

- Companies have no clear guidelines for supplier segmentation in place. Supplier segmentation is essential to understand which suppliers are ready for a more digitalized relationship.

- Most of the employees within the procurement department are not familiar with the management guidelines of supplier relationship or the tools to be used to optimize the expected output of those 
relationships. This is still a very relevant issue to consider when discussing Procurement 4.0. Employees in this area are not accustomed to referring to a huge variety of methods for supporting operational or strategic performance of procurement.

- A team approach [43] is necessary to exploit the digital potential of suppliers. Suppliers should be integrated into any kind of strategic renewal process as early as possible, especially when setting up supplier touchpoints along a digital supplier journey (see figure 3).

- Despite the fact that most of the companies are aware of the importance of long-term relationships [44] for the future success of a procurement department, so far they are not standard. The implementation of long-term partnerships requires an investment of time, money and personal resources. Investing into strategic goals is still the exception within procurement. As mentioned previously, the focus on operational activities in bringing down costs is predominant in procurement.

- Finally, suppliers cannot express their degree of satisfaction with the existing relationship. Whereas a measurement tool for customer satisfaction is standard to have in place in sales, this is yet to become practice for suppliers. Much helpful information is then lost that could have otherwise been used for improving the relationship and gaining insight into how to optimize the output of this relationship.

The collected data allows us to put forward several suggestions with respect to redesigning supplier relations in times of Procurement 4.0. The first step of the previously presented conceptual model for Procurement 4.0 - automation - enables procurement to concentrate on value adding activities. Supplier segmentation and evaluation are processed automatically. The collected data can be used as basis for generating reports and transmitting the results to all involved stakeholders as an information base for further actions to be taken. User-friendly procurement tools and systems encourage individualism in purchasing. Key account supplier managers are put in position to optimize relationships based on personalized data of suppliers. This supplier-centered approach strengthens interaction and promotes innovation. Online communication platforms and knowledge databases serve the same purpose.

The activities taking place in the context of digital supplier relationship management within German companies are aligned to the different technologies used in Procurement 4.0 presented in chapter 4. Finally, possible supplier touchpoints along a digital journey are discussed to draw up a future vision of a digital supplier buyer relationship.

\subsection{Identifying Unidentified Potential: Does Digital}

\section{Supplier Relationship Management Already Exist?}

Figure 2 identifies several areas where Procurement 4.0 technologies are not yet implemented. In particular, Cyber Physical Systems and Internet of Things are not utilized at all. Some ideas how to use innovative and not yet implemented technologies in procurement function are found in figure 3. Cloud solutions help to manage and store supplier information centrally to increase transparency in relationships. Supplier management tools can be handled easily in a Cloud with simple access and the opportunity to obtain required information in a timely manner.

This does not apply to Big Data. Almost every identified hurdle towards supplier relationship management can be overcome by using Big Data for segmenting and evaluating suppliers, even when guidelines within a company are still missing. It is simple to verify which of the suppliers are important and new technologies can be used to automate the less complex categories. Big Data can help to reveal the future innovative capability of a supplier as well as the potential to implement cost saving programs, rather than focusing only on past data. Furthermore, Big Data enables the efficient monitoring of buyer-supplier-relationships. Regular forecast on future projects may provide suppliers with opportunities to innovate and come up with suitable recommendations. Knowledge databases for buyers, suppliers and requisitioners foster innovation efforts and collaboration. Large amounts of data can be controlled in order to optimize purchasing solutions. Above all, as a relatively new application in the context of procurement, prescriptive analytics help to point out possible results and to determine the next steps in a successful supplier relationship [36]. With ever-increasing complexity of global supply chains, Big Data can make a significant contribution to providing real-time information about supply chain outcomes that may lead to significant disruptions. The aim is to avoid "supply chain disruption" and thus production downtime. A critical issue to point out is that at present data must be exchanged that was previously considered too sensitive for data exchange [45].

Chatbots or RPA systems can help. In the negotiation process, these digital technologies are able to build a variety of risk scenarios that can be used as a confidence-building measure in relationship management. By outlining the sensitivity of this data and how carefully the purchaser is willing to handle it, this allows the supplier to disclose more important information required in order to avoid disruptions. And if we think one step further, AI-solutions can learn this behavior in negotiations and thus contribute to securing long-term buyer-supplier-relationships. The assignments made in Figure 2 are to be understood as future possibilities in the area of AI. Currently, AI-solutions are only taken for supplier evaluation and the maintenance of master data. 
These processes can be supported by online "supplier one-pagers" displaying key supplier information and providing stakeholders with useful performance metrics, current project evaluations or relationship development measures. Long-term relationships can be underpinned by having automatically renewing contracts in place or referring to automatically generated reports for data-driven contract extension decisions.

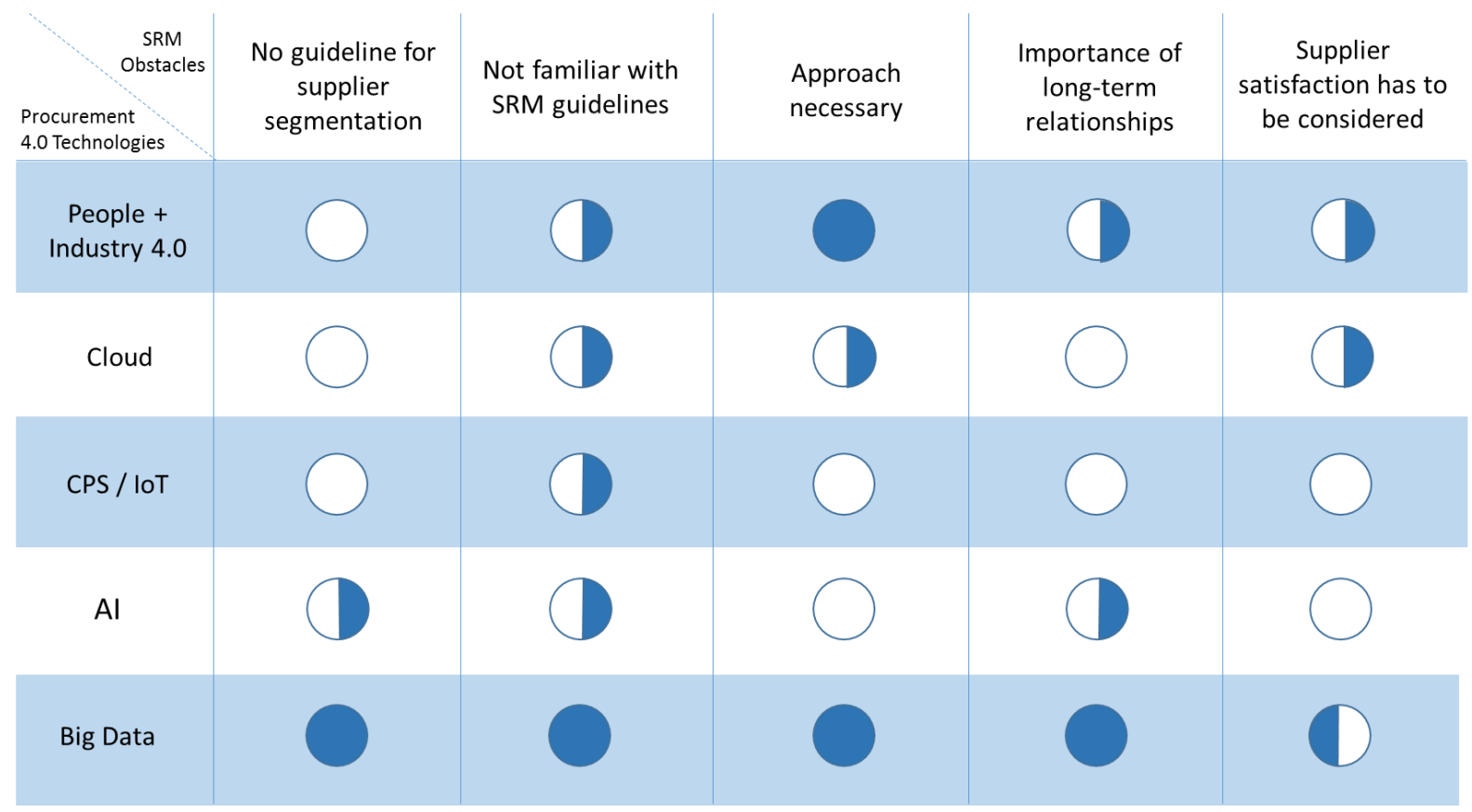

Figure 2. Identifying potential: Where can companies improve? [own illustration]

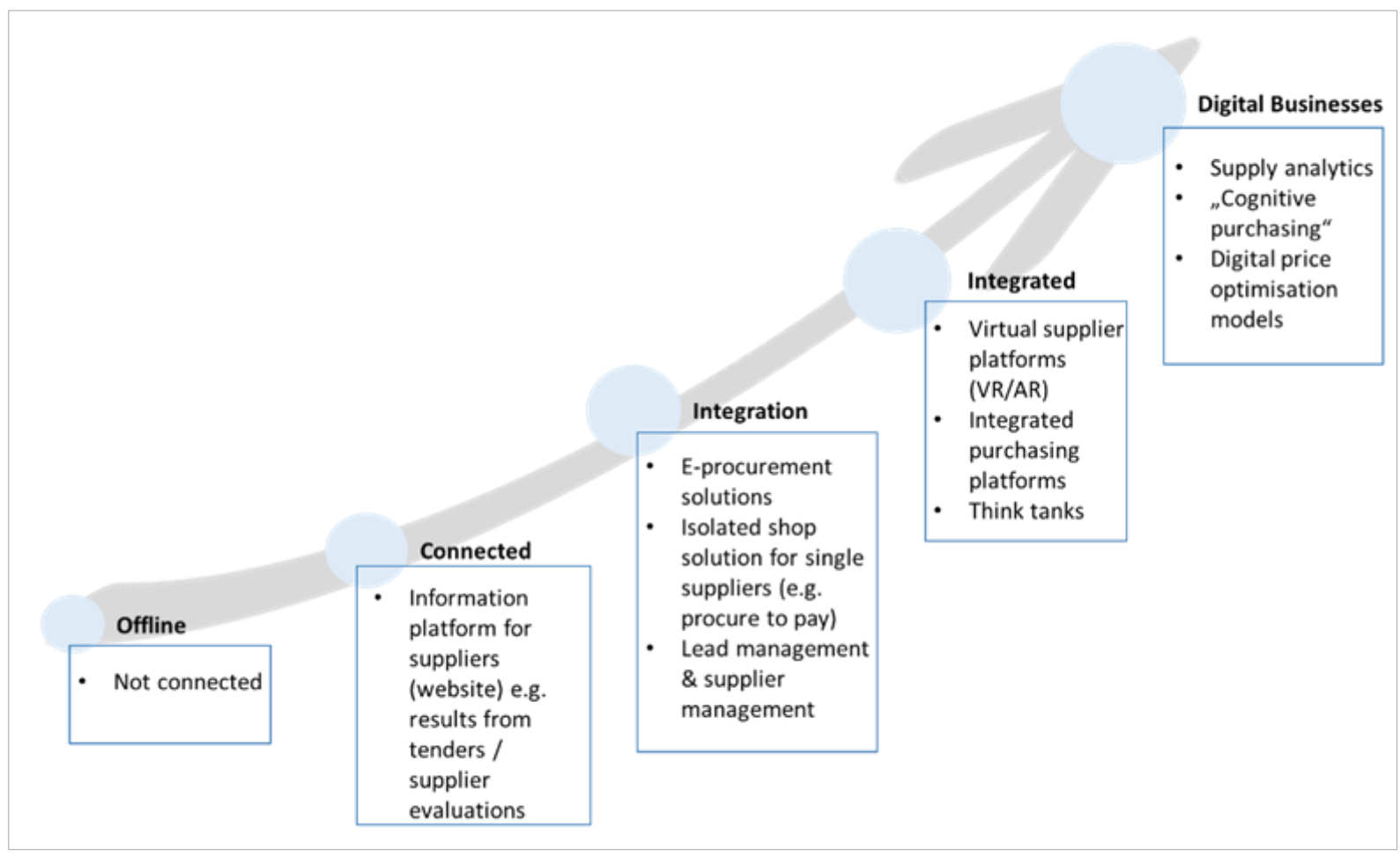

Figure 3. Digital Supplier Relationship Model: Supplier touchpoints [own illustration] 
With reference to the previously described conceptual model for Procurement 4.0, digital transformation starts with people, and therefore education and communication play a major role in fostering this process. The problem is not so much that technologies such as AI replace the efficient management of buyer-supplier-relationships; rather, employees in purchasing and at the suppliers' company do not have the necessary skills and competences to take advantage of the opportunities offered by new digital technologies [31], as illustrated in figure 2. Beside the aforementioned online communication platforms for exchanging information with suppliers, the need for cross-functional teams can be anticipated and more intense collaborations can be realized, for example by using virtual meeting software. In this way, these teams not only contribute to increasing efficiency in a relationship and increasing innovative output - as discussed in the previous chapters - but also jointly set uniform data and system standards so that the corresponding digital technologies can process a homogeneous volume of data as efficient as possible [46]. Like newly implemented tools for supplier management, this requires trainings or roadshows addressing purchasers as well as suppliers to exploit the full potential of the digital journey.

Figure 2 reveals that there is room for improvement when digitalizing supplier relationship management. Due to this finding, the authors used the customer journey approach [47] to establish a future Digital Supplier Relationship Model (see figure 3), which is also increasingly being used in procurement [48].

The digital journey starts "offline" - there is no digital connection between buyers and suppliers in place. "Connected" represents for example company websites where suppliers have limited access to past evaluation data or future demand of the company to place an offer or take part at an online auction. In the "integration" phase, traditional e-procurement solutions or isolated shop solutions for single suppliers (such as procure to pay) are implemented. "Integrated" covers virtual supplier platforms for example by using Virtual Glasses to support buyers in their production or construction processes. Another example can be integrated purchasing platforms where suppliers support each other. If one supplier has quality issues and is not capable of delivering the procurement item in time another supplier will take over the order. Suppliers organize themselves in such a way that they meet the purchaser's requirements without the involvement of the purchasing department. The final stage of "Digital Business" comprises supply analytics, "Cognitive Purchasing" or digital price organization models. Cognitive procurement refers to methods that use disruptive technologies, e.g. in order to use buyer-supplier- relationships to better achieve objectives of the purchasing company. As already outlined at the beginning of this chapter, purchasing is a very data-intensive function and therefore ideally suited to profit from competitive technologies. Initial approaches already exist that enable procurement departments to forecast demand without being dependent on obtaining the required information in time anymore. Completely new approaches of optimizing purchasing processes will evolve. Thus, "agility" is the essential advantage of a digital relationship with suppliers. The purchasing function not only improves its ability to react to internal requirements, but also to changes in the sales market. The "informative" dependency of purchasing on other corporate functional areas is significantly reduced. Figure 3 is based on actual studies from the field of Procurement 4.0 [49-54].

In summary, Procurement 4.0 requires an appropriate strategic and leadership approach, while top management support is essential to realize the digital vision of a procurement department. As stated above, the relationship focus is crucial and the most important question in this respect is: "Do we really understand our suppliers in a digital environment"? Organizational support and funds are needed to attract and keep digital talents who can successfully manage digital relations with suppliers. In order to support organizational requirements, a procurement department depends on the right digital processes, control mechanism and tools [51].

\section{Conclusions and Limitation}

This is what "digital reality" in Germany looks like! Purchasing is seen as the most important contributor to future value and innovation. In this context, tools for digitalization are mostly recognized. The problem that emerges regards differences of opinions on how to use and implement those tools. Some companies have already achieved a certain level of proficiency, for example with AI solutions in place, while others are still struggling with the introduction of rudimentary e-procurement solutions. The reason why Procurement 4.0 has not progressed more rapidly can be traced to its inability to reach a higher maturity level in purchasing thus far (see chapter 2). Another reason is the suboptimal positioning of the procurement department. In many companies, procurement has not yet reached the C-level, which results in the previously mentioned lack of top management support. Finally, procurement still suffers from missing resources and budget. Keeping in mind these findings, a successful digital journey of procurement should be possible.

The researchers are aware of the fact that issues can be raised with the methodological approach. The aim of this research project is to bring together existing results from qualitative and quantitative studies, which have already been conducted by the researchers in similar contexts, in order to develop a conceptual framework for the 
digitalization of supplier management. Numerous quantitative studies have been conducted in the last two years with a focus on Purchasing 4.0. The most relevant studies can be found in the bibliography. However, their significance and implications for practice are very limited and proves the present research gap. Views of digitization in the function procurement vary too widely. Rather the attempt has been made to bring together relevant empirical results from partial studies and to develop from them a conceptual framework for a digital supplier relationship management approach. Based on concrete examples from procurement policy practice, various digital tools were analyzed in order to arrive at initial statements about their relevance to problem solving. The results of this paper can now be used in a next step to put in place a quantitative study design. This will more clearly enable valid predictions as to what the digital future of buyer-supplier-relationships may look like and how they will contribute to securing the future of a company.

\section{REFERENCES}

[1] E. Fröhlich, A. Karlshaus (2017). Status Quo: Personalentwicklung in der Beschaffung - Ergebnisse einer empirischen Studie. Personalentwicklung in der Beschaffung [Status Quo: Personnel development in procurement - Results of an empirical study. Personnel development in procurement], ed. by E. Fröhlich / A. Karlshaus, Wiesbaden 2017, 1-25, DOI: 10.1007/978-3-662-50510-6_1.

[2] O. Knapp, S. Marlinghaus, F. Hammermeister, S. Miczka, M. Zollenkop. Procurement endgame: The future of procurement in times of digitalization and disruption. Roland Berger GmbH. 2018 Online available from https://www.rolandberger.com/de/Publications/Procureme nt- has-entered-the-final-stage-of-transformation.html.

[3] K. Nowosel, A. Terrill, K. Timmermann. Procurement next Frontier - The Future Will Give Rise to an Organization of One, Accenture Strategy. 2015 Online available from https://www.accenture.com/_acnmedia/pdf-52/accenture-di gital-procurement-next-frontier.pdf.

[4] E. Fröhlich, K. Steinbiß, M. Wexford Whelan,. Lieferantenmanagement im Zeitalter der digitalen Transformation [Supplier management in the age of digital transformation]. Journal of Engineering, Management and Operations, Vol. 1, No. 1, 153-164, 2018.

[5] E. Fröhlich, K. Steinbiß. Procurement Goes Digital: The Supplier Relationship Management Case, in: International Symposium on Business and Economics. Global Science Institute, Podgorica 2018, 32-40, 2018. ISBN: 978-605-81246-1-5.

[6] P. Kraljic. Purchasing Must Become Supply Management. Harvard Business Review, Vol. 61, No. 05, 109-117, 1983. Online available from http://abaspro.com.ar/wp-content/ uploads/2019/05/Kraljic.pdf.

[7] J. Wilson. Essentials of Business Research, London 2010.
[8] S. Laws, C. Harper, N. Jones, R. Marcus, R. Research for Development: A Practical Guide. 2nd ed., London: Sage 2013.

[9] M. Saunders, P. Lewis, A. Thornhill. Research Methods for Business Students, Harlow 2016.

[10] A. Bryman, E. Bell. Business Research Methods, 4th ed., London 2015.

[11] A. Bryman. Research Methods and Organisation Studies. London 2000.

[12] A. Saldana. Fundamentals of Qualitative Research, London: Oxford University Press 2011.

[13] Quinlan, C. (2011). Business Research Methods, Cengage Learning EMEA.

[14] A. Bryman. Social Research Methods, 5th ed., London 2016.

[15] E. Grochla: Einführung in die Organisationstheorie [Introduction to Organizational Theorie], Stuttgart 1978, DOI: 10.1007/978-3-322-86022-4_7.

[16] C. Radell, D. Schannon. Digital Procurement: The Benefits Go Far Beyond Efficiency. Bain \& Company, Inc. 2018. Online available from https:// www.bain.com/contentassets/ 72e381c9155b467db6e8e4ac93ee6ac1/bain_brief_digital_ procurement_the_benefits_go_far.pdf.

[17] A. Lockamy III, K. McCormack. The development of a supply chain management process maturity model using the concepts of business process orientation. Supply Chain Management: An International Journal, Vol. 09, No. 04, 272-278, 2004, DOI: 10.1108/13598540410550019.

[18] B. Kewell, R. Adams, G. Parry. Blockchain for good? Strategic Change, Vol. 26, Issue 5, 429-437, 2017, DOI: $10.1002 /$ jsc. 2143 .

[19] G. Schuh, C. Reuter, A. Hauptvogel, C. Doelle. Hypothesis for a Theory of Production in the Context of Industry 4.0. Advances in Production Technology, ed. by C. Brecher, 11-23, 2015, DOI: 10.1007/978-3-319-12304-2_2.

[20] V. Koch, S. Kuge, R. Geissbauer, S. Schrauf. Industry 4.0 opportunities and challanges of the industrial internet. 2014. Online available from https://www.pwc.nl/en/assets/ documents/pwc-industrie-4-0.pdf.

[21] McKinsey \& Company. Industry 4.0 at McKinsey’s model factories. Get ready for the disruptive wave. 2016. Online available from https://capability-center. mckinsey.com/file s/mccn/2017-03/digital_4.0_model_factories_brochure_2. Pdf.

[22] J. M. Cavanillas, E. Curry, W. Wahlster. The Big Data Value Opportunity, in: New Horizons for a Data-Driven Economy, ed. by J. M. Cavanillas, E. Curry, W. Wahster, 3-11, 2015, DOI: $10.1007 / 978-3-319-21569-3 \_1$.

[23] D. Arunachalam, N. Kumar, J. P. Kawalek. Understanding big data analytics capabilities in supply chain management: Unravelling the issues, challenges and implications for practice. Transportation Research, Part E 114, 416-436, 2017, DOI: 10.1016/j.tre.2017.04.001.

[24] A. Gunasekaran, T. Papadopoulos, R. Dubey, S Fosso-Wamba, S. J. Childe, B. Hazen, S. Akter. Big data 
and predictive analytics for supply chain and organizational performance. Journal of Business Research, Vol. 70, 308-317, 2017, DOI: 10.1016/j.jbusres.2016.08.004.

[25] L. Esterle, R. Grosu. Cyber-physical systems: Challenge of the 21st Century. Elektrotechnik und Informationstechnik [Electrical engineering and information technology], Vol. 133, No. 7, 299-303, 2016, DOI: 10.1007/s00502-0160426-6.

[26] A. Gilchrist. Industry 4.0. The Industrial Internet of Things, New York 2016, DOI: 10.1007/978-1-4842-2047-4.

[27] A. Rymaszewska, P. Helo, A. Gunasekaran. IoT powered servitization of manufacturing - an exploratory case study. International Journal of Production Economics, Vol. 192, 92-105, 2017, DOI: 10.1016/j.ijpe.2017.02.016.

[28] P. Buxmann, H. Schmidt. Künstliche Intelligenz: Mit Algorithmen zum wirtschaftlichen Erfolg [Artificial Intelligence: With Algorithms to economic success]. Wiesbaden: Gabler Verlag 2019, DOI: 10.1007/978-3-66257568-0.

[29] BME. Digitalisierung in Supply Chains [Digitalization in Supply Chains]. Eschborn 2019. Online available from https://www.researchgate.net/publication/331743260_BM E-Logistikumfrage_Digitalisierung_in_Supply_Chains.

[30] Jaggaer. Digitale Transformation in der Beschaffung: Wie weit sind wir wirklich? [Digital Transformation in Procurement: How far have we really gone?], München. 2019 Online available fromhttps://go.jaggaer.com/de/dl_di gital_procurement_rep.

[31] K. E. Kushida, J. Kurray, J. Zysman. Diffusing the Cloud: Cloud Computing and Implications for Public Policy. Journal of Industry, Competition and Trade, Vol. 03, No. 11, 209-237, 2011, DOI: 10.1007/s10842-011-0106-5.

[32] S. Narayanan, V. Sambamurthy, T. Y. Choi. Getting Value from the Cloud. Supply Chain Management Review, Vol. 56, No. 02, 32-37, 2017. Online available from https://ww w.logisticsmgmt.com/article/getting_value_from_the_clou d.

[33] B. W. Wirtz. Digital Business Models: Concepts, Models, and the Alphabet Case Study, Cham 2019, DOI: 10.1007/ 978-3-030-13005-3.

[34] BME. BiP eSolution Report, Frankfurt a. Main 2019. Online available from https://www.bme.de/fileadmin/_horusdam/ 8270-Mediadaten-2019_eSOLUTIONS-REPORT.pdf.

[35] T. Piesold, E. Fröhlich. Marktüberblick zu E-Procurement-Lösungen bei Energieversorgern [Market overview of e-procurement solutions for the energy sector], Leipzig 2018.

Online available from https://www.energieforen.de/portal/ media/geschuetzt/usergroups_3/einkauf/8_at_2/05_UG_Ei nkauf_Befragung_EProcurement-Loesungen.pdf.

[36] K. Yap, C. C. Wong, Y. H. Koh. Procurement: Riding the Transformative Digital Wave, Seoul 2018.

[37] C. H. Glock, E. H. Grosse, J. M. Ries. Decision Support Models for Supplier Development. Systematic Literature Review and Research Agenda. International Journal of Production Economics, No. 193, 798-812, 2017, DOI: 10.1016/j.ijpe.2017.08.025.
[38] G. Lechner. Contribution of Supplier Management to Company Value Development, Eurasian Journal of Business and Management, Vol. 7, Issue 2, 38-48, 2019, DOI: 10.15604/ejbm.2019.07.02.004.

[39] G. Heß. Strategischer Einkauf und Supply-Strategie. Schrittweise Entwicklung des strategischen Einkaufs mit der 15M-Architektur 2.0 [Strategic Procurement and Supply Strategy. Stepwise Development of Strategic Procurement with the help of the 15M-Architecture 2.0]. 4th ed., Wiesbaden 2017, DOI: 10.1007/978-3-658-16215-3.

[40] Z. Q. Li, H. C. Tan, C. Anumba, F. C. Chia. Development of a Web-based System for managing Suppliers' Performance and Knowledge Sharing in Construction Project. Built Environment Project and Asset Management, Vol. 7, No. 2, 117-129, 2017, DOI: 10.1108/BEPAM-10-2015-0061.

[41] Krudewig, M.: Supplier Development in Times of "Procurement 4.0": Unpublished Master Thesis at the CBS, Cologne Business School, 2018

[42] R. K. Yin. Case Study Research and Application, 6th ed., Los Angeles 2018.

[43] E. Fröhlich. CSR und Beschaffung. Theoretische wie praktische Implikationen eines nachhaltigen Beschaffungsprozessmodells [CSR and Procurement. Theoretical and practical implications of a sustainable procurement process model]. Berlin / Heidelberg 2015, DOI: $10.1007 / 978-3-662-46231-7$

[44] P. Spiller, N. Reinecke, D. Ungermann, H. Teixeira Procurement 20/20, Hoboken 2014.

[45] B. Otto, M. ten Hompel, S. Wrobel. Industrial Data Space, in: Digitalisierung: Schlüsseltechnologien für Wirtschaft und Gesellschaft [Digitalisation: Key technologies for business and society], ed. by R. Neugebauer, 111-134, 2018, DOI: 10.1007/978-3-662-55890-4.

[46] L. von Lüninck, F. Wader. Digital Procurement. Digitalisierung im Einkauf muss alle mitnehmen. Industrieanzeiger, Vol. 21, p. 32, 2018. Online available from

www.konradin-service.de/pdfarchiv7/share/ia_2018-021_9 6.pdf.

[47] A. Richardson. Using customer journey maps to improve customer experience, 2010. Online available from https://hbr.org/2010/11/using-customer-journey-maps-to.

[48] L. Schwalbach. Einkauf 4.0 - Umsetzung der Digitalisierung [Procurement 4.0 - Implementation of Digitalisation], Norderstedt 2018.

[49] BMÖ. Einkauf 4.0. [Procurement 4.0], ed. by C. Vollrath, M. Klemen and $\mathrm{H}$. Pechek, 2015. Online available from http://www.bmoe.at/downloads/Studien/ Studie_Einkauf_ 4.0_BM_IMP.pdf.

[50] CPO Survey (2018). What's the Next Big Thing in Procurement? ed. by M. Vollmer and K. Machhol, 2018. Online available from https://www.ariba.com/resources/ library/library-pages/ cpo-survey-2018.

[51] Deloitte LLP. Leadership: Driving Innovation and delivering impact. The Deloitte Global Chief Procurement Officer 
Survey 2018. Online available from https://www.deloitte.c om/de/de/pages/operations/articles/cpo-survey-2018.html.

[52] KPMG. Energy \& Natural Resources: Strategic Procurement and M\&A Insights, 2014. Online available from https://ho me.kpmg.com/content/dam/kpmg/pdf/2014/10/m-and-a-str ategic-procurement-insight-recap.pdf.

[53] PWC. Supplier Relationship Management. How key Suppliers drive your Company's Competitive Advantage, 2017. Online available from https://www.pwc.nl/nl/assets/ documents/pwc-supplier-relationship-management.pdf.

[54] PWC. Procurement 4.0. Are you ready for the Digital Revolution? 2018. Online available from https:// www.stra tegyand.pwc.com/media/file/Procurement-4.pdf. 